\title{
Green building Technology of Prefabricated Building
}

\author{
Li sheng Chen ${ }^{1}$ \\ ${ }^{1}$ Teaching And Research Office For Architecture, The Tourism College of Changchun University, Shuangyang District, Changchun City, \\ China
}

\begin{abstract}
With the development of my country's economy and the progress of society, the current process of urbanization in my country is accelerating, fresh blood is constantly added in the field of construction, and prefabricated buildings are born. Based on this, this article starts with the advantages and development trends of prefabricated buildings, conducts in-depth research and exploration on the key technologies of green buildings, and attempts to provide some reference for the future development of prefabricated building technologies.
\end{abstract}

\section{Introduction}

Prefabricated construction is an important part of my country's construction industry, and green building technology is its core content. Through the analysis and research of green building technology by experts, we know that in the overall work flow of prefabricated buildings, professional technology, management methods and equipment need to be continuously improved and updated ${ }^{[1]}$. Therefore, my country needs to increase its promotion in this area to lay the foundation for technical reforms in my country's construction industry.

\section{Advantages of prefabricated buildings}

Prefabricated buildings are buildings constructed using industrial production methods. Most of the components in the buildings are transported to the construction site through special channels after the factory chemical industry for assembly operations. This way of working omits the traditional construction operations, and the cost-effectiveness of construction, decoration, and construction and assembly buildings is higher,which is consistent with the green requirements of the construction industry ${ }^{[2]}$.

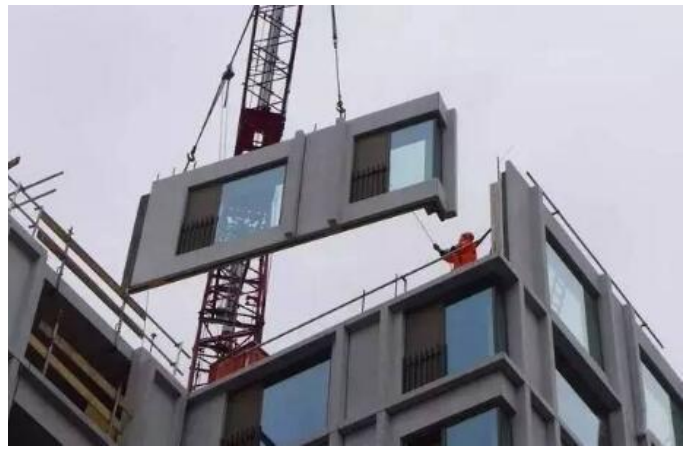

Fig.1. Construction site of prefabricated assembly components

The advantages of prefabricated buildings have the following characteristics:

- The concrete quality of the exterior of the building is better;

- The exterior appearance of the prefabricated building is beautiful;

- Prefabricated buildings can be combined with steel components and constructed to facilitate production.

\section{The development trend of prefabricated buildings}

From the perspective of development trends, the overall layout and prefabricated components of prefabricated buildings will incorporate fresh elements. The building structure and the surrounding environment are integrated into the prefabricated building, adding a bit of vitality and vitality to the development of the prefabricated building.

At present, my country's prefabricated construction is still in the development stage, and a series of problems such as design, production, transportation and installation

\footnotetext{
* Corresponding author:525802150@qq.com
} 
have become the key problems that need to be overcome in the practical stage. In the future development of prefabricated buildings, while overcoming the immediate problems, design aesthetics and functional realization should be the priority factors. By innovating and improving the construction technology in the construction process and promoting the overall development of the industrial chain of construction links such as engineering design, installation and construction, and logistics management, the construction industry and related enterprises have therefore ushered in new opportunities and strive to meet the development requirements of the times.

\section{Scientifically and reasonably study the application of prefabricated building construction technology}

\subsection{Reasonable and effective application of precast component concrete pouring construction technology}

When pouring the prefabricated components, the relevant staff must fully inspect the pouring equipment, and take the quality of the reinforcing steel materials used in the construction as the focus of the work. Only when the quality of the steel bar materials used in the construction meet the standards can the quality of the concrete construction equipment in the project meet the specific project operation requirements ${ }^{[3]}$.

Before the construction, the staff strictly inspected the operation process of precast concrete pouring to check whether the operation process complies with the specifications and the actual pouring effect to ensure that the construction process is highly consistent with the design standards. Once the deformation is found, it should be reported as soon as possible and repair work should be carried out in time ${ }^{[4]}$. When the pouring link in the prefabricated building is completed, the staffs appropriately adjust the flatness of the plane based on the actual situation, and carry out the corresponding maintenance work to meet its technical requirements to the greatest extent. (See Table 1) When the concrete project is completed, the staff can use maintenance techniques such as steam curing to scientifically and effectively carry out maintenance work on the surface of the precast components.

Table 1. Key points of concrete pouring construction

\begin{tabular}{|c|c|}
\hline Slump & $100 \mathrm{~mm}$ \\
\hline Water-cement ratio & 0.35 \\
\hline $\begin{array}{c}\text { The moving distance of } \\
\text { the vibrator }\end{array}$ & $\leq 300 \mathrm{~mm}$ \\
\hline Vibration time & $30 \mathrm{~s}$ \\
\hline
\end{tabular}

\subsection{Commonly used construction techniques}

The main function of the prefabricated internal shear wall is to ensure the accurate internal connection of the building, meet the specific needs of construction technology, optimize and upgrade the prefabricated technology, and use bolts to tightly connect the prefabricated components inside the building ${ }^{[5]}$. (As shown in table 2)

Table 2. Construction points of precast inner shear wall

\begin{tabular}{|c|c|}
\hline $\begin{array}{c}\text { Grouting curing } \\
\text { time }\end{array}$ & 28days \\
\hline $\begin{array}{c}\text { Measured value of } \\
\text { tensile load }\end{array}$ & 1.15 times \\
\hline Stirrup spacing & $\leq 80 \mathrm{~mm}$ \\
\hline Grouting time & $\leq 30 \mathrm{~min}$ \\
\hline
\end{tabular}

When assembling prefabricated components, be sure to leave enough space between the lower slabs to lay the foundation for the subsequent insertion of steel bars, and use bolt connection to connect the prefabricated building shear wall and the main project together. (Figure 2) When carrying out prefabricated building construction work, the connection between prefabricated components is mainly realized with corresponding fasteners. And in order to get a tight connection of the prefabricated components and prevent the fasteners from loosening, it is necessary to implant steel bars in the prefabricated inner shear wall and pour cement mortar into the holes of the fasteners. This can further improve the overall reliability and stability of prefabricated buildings.

Fig. 2. Bottom view of prefabricated load-bearing wall sandwich panel

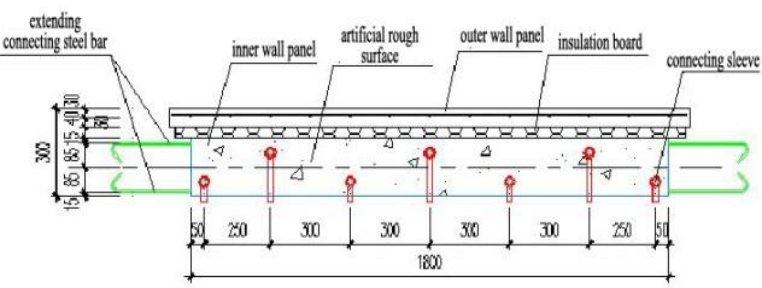

\subsubsection{Pre-made forms}

The window materials should be selected scientifically and reasonably to ensure that the materials meet the collective requirements of the architectural design and also meet the functions of the windows themselves and the outside world for ventilation and light transmission. During the construction of the prefabricated windows, the staff must firmly fix the bolts on the windows and reserve a suitable position for the nuts. (Figure 3)

\subsubsection{Prefabricated internal shear wall}




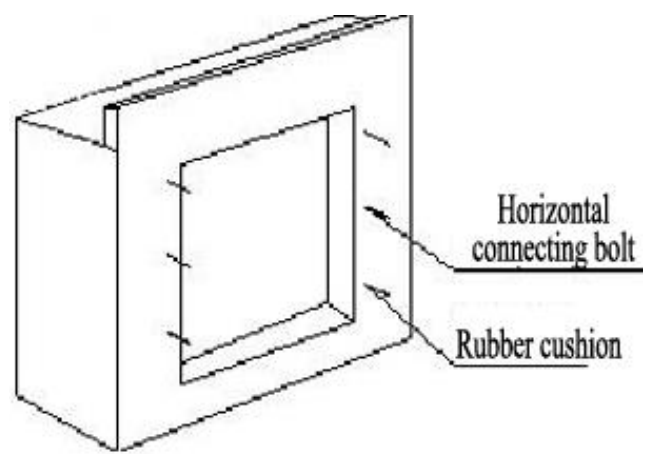

Fig. 3. Schematic diagram of installation of prefabricated windows

In order to ensure the installation quality and construction safety when installing the windows, the connection between the windows and the components should be adjusted continuously until a suitable installation position is found.

\subsubsection{Prefabricated laminated board}

As a common technology in prefabricated construction, the laminated board has been widely used. The distance between the laminated board and its working layer is kept at $300 \mathrm{~mm}{ }^{[6]}$. In order to eliminate errors in the installation process, the installer can make appropriate internal adjustments to the installation direction according to the actual situation to ensure the accuracy of the installation. (As shown in table 3)

Table 3. List of prefabricated laminated panels

\begin{tabular}{|c|c|}
\hline $\begin{array}{c}\text { Distance to working } \\
\text { floor }\end{array}$ & $300 \mathrm{~mm}$ \\
\hline Support distance & $150 \mathrm{~cm}$ \\
\hline Strength & $\geq 70 \%$ \\
\hline $\begin{array}{c}\text { Time control after } \\
\text { pouring }\end{array}$ & $2-5$ days \\
\hline
\end{tabular}

Use cast-in-place laminated layer to connect beams, walls and laminated slabs. That is, after the composite slab is hoisted to an accurate position, the composite slab reinforcement is anchored into the beam wall, and the concrete is poured after rechecking that the standard and design requirements are met to meet the requirements of the beam-wall panel connection ${ }^{[7]}$. (Figure 4,5 )

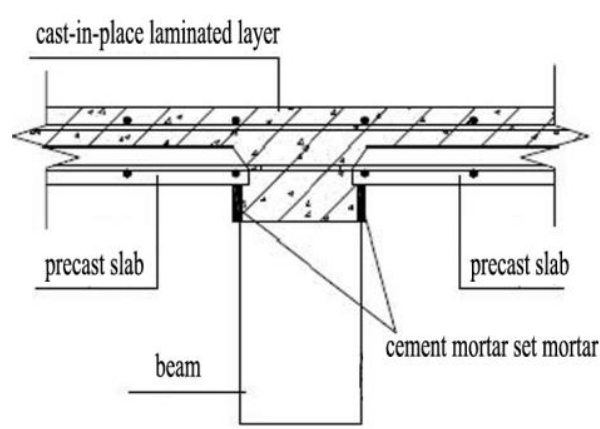

Fig. 4. Connection diagram of prefabricated laminated slab and

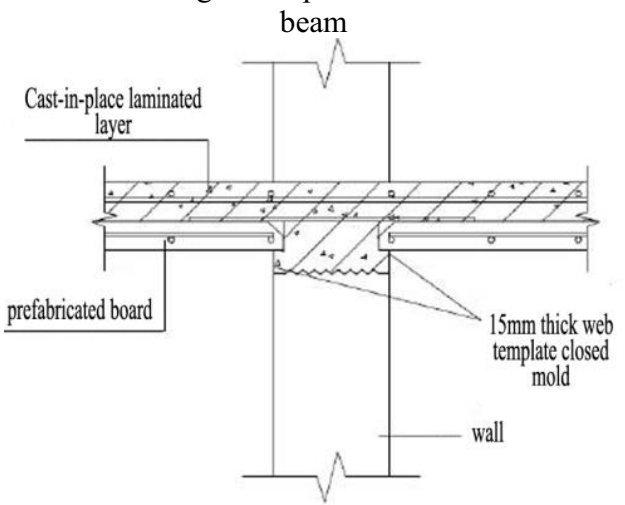

Fig.5. Connection node diagram of prefabricated laminated board and wall

The connection between the laminated boards is connected by the board strap. Before hoisting, the position line of the laminated floor slab strip will be popped up on the lower concrete slab. After hoisting in place, the slab strip position between the laminated slabs will be supported. After tying the cast-in-situ rebars, the slab concrete will be poured to connect the laminated slabs ${ }^{[8]}$. (Figure 6)

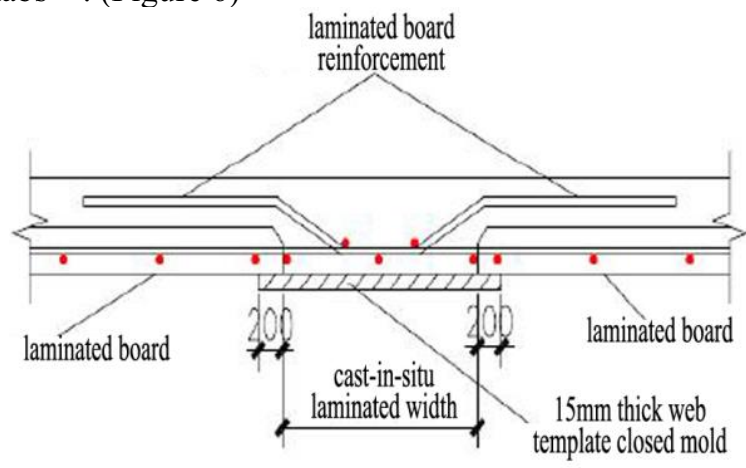

Fig. 6. Connection node diagrams of prefabricated laminated board and board

\section{Key Technologies of Green Building}

\subsection{Establish a model guide system}

In order to improve the efficiency of construction and ensure the quality of the project, in the practical application of green construction projects, a model guide system is established in the construction preparation stage ${ }^{[9]}$. This system can effectively solve the problem of 
building waterproofing and structural connection. However, this system needs to be reviewed and approved by the construction unit and design unit before it is established, and can be applied and widely promoted after passing the review ${ }^{[10]}$.

\subsection{Logistics management technology of prefabricated components}

In the construction phase of a construction project, in order to coordinate the supply time of the structure, the construction unit appropriately introduces the logistics management that meets the demand for the use of building materials into the construction of the construction project in accordance with the specific work requirements and logistics management methods. On this basis, the building materials are divided into specific categories to facilitate the effective development of follow-up work.

\subsection{High-precision quick-release combined formwork construction}

Before the start of the construction work, the management personnel must have an in-depth understanding of the construction drawings, and accurately grasp the construction procedures of the construction equipment, and then carry out the quickrelease combined construction on the inner side of the building's external wall panels. The specific construction process is relatively intuitive. In order to save the amount of wood used, the construction is carried out by means of a directional fixed connector and a five-section screw. The final construction process of the aluminum film refers to the premise of the positioning of the wall pillars, the installation of the elevation of the wall, and the related flatness inspection and process inspection according to the installed girder template ${ }^{[11]}$.

\section{Conclusions}

To sum up, as my country's economic development continues to accelerate, the country's efforts to remediate environmental pollution have also increased. In the field of construction, in order to follow the pace of national development, prefabricated buildings promote the upgrading and development of green buildings through innovative reform technologies. As a result, the construction industry in our country ushered in vitality while also promoting the continuous development of the construction field.

\section{References}

1. Xiao, M.H., Zhang, B. (2018) Prefabricated building construction technology. China Construction Industry Press, 6: 36-45.78.

2. Li, F. (2020) Research on Green Building Technology of Prefabricated Buildings. Value Engineering, 19: 189-190.

3. Tang, S. Exploring prefabricated building construction technology. Global Market, 7: 274

4. Li, L., Zheng, P. (2020) Exploring prefabricated building construction technology. Building materials and decoration, 1: 49-50

5. Ma, Q., Ma, Z.Y. (2020) Prefabricated building construction technology research. Urban construction theory research (electronic version), 16: 62

6. Wu, L.W. (2020)Research on prefabricated building construction technology. Commodity and quality, 6: 73

7. Tang, C.Y. (2018)Research on the application and promotion of prefabricated buildings. Southwest Jiaotong University.

8. Lu, Y. (2019) Prefabricated building structure system and design application based on the concept of green energy saving. Smart buildings and smart cities, 8: $51-53$

9. Liu, Y. (2020) Research on prefabricated building construction technology. Building materials development orientation, 6: 266

10. Zhang, J.S. (2020)Deepening research on the design of precast concrete fully assembled office building. Proceedings of the 2020 Industrial Architecture Academic Exchange Conference (Volume 1), Industrial Architecture Magazine, 337-340.

11. Qiu, D., Pan, F., Zhang. C.J., Han, Y.M. (2016) Analysis of Green Construction Technology of Prefabricated Buildings. Green Building, 03: 63. 